\title{
Construction situation, costs and charges associated with pharmacy intravenous admixture services: multi-center cross- sectional survey based on 137 medical institutions in mainland China
}

\author{
Chunsong Yang ${ }^{1,2}$, Bing Yao Kang ${ }^{3}$, Lingli Zhang ${ }^{1 *}$ and Dan Yu ${ }^{4}$
}

\begin{abstract}
Background: To investigate the construction situation, costs and charges associated with pharmacy intravenous admixture services (PIVAS) to provide references for the construction and development of PIVAS in mainland China.

Methods: A multi-center cross-sectional survey was conducted via a WeChat Group targeting PIVAS leaders in hospitals to investigate the basic situation of PIVAS, including opening time, area, number of PIVAS, equipment, management mode, PIVAS costs and charges, as well as numbers of beds, open wards, and staff, and analyze differences in PIVAS construction at different provincial and hospital levels.

Results: 137 questionnaires were collected from 29 provinces, representing a response rate of 99.3\%. Most participants (88.4\%) were from Level III Hospitals. The number of years of operations of PIVAS ranged from 1 to 22 (median: 6). PIVAS site area ranged between 100 and $1973 \mathrm{~m}^{2}$; daily average infusion volume was concentrated in the ranges $0-1000$ bags $(29.9 \%, 41 / 137)$ and $1001-2000$ bags $(26.3 \%, 36 / 137)$. In terms of PIVAS management mode, the vast majority used separate pharmacy management $(65.0 \%, 89 / 137)$. Only 52.6\% (72/137) of PIVAS have standardized charges, and $70.1 \%$ (96/137) operate at a loss. The median costs of mixed tumor chemotherapy drugs, total parenteral nutrition, general medicine, antibiotics were 20,35, 4 and 5 RMB, respectively. With the exception of a few features, PIVAS construction does not obviously differ among different regions and hospital levels.

Conclusions: In recent years, PIVAS in China has developed rapidly and become relatively large. The main problems are that most provinces lack standards for charges and PIVAS construction differs among hospitals. Therefore, standards for PIVAS construction and charges should be developed to provide a reference for the future development of PIVAS.
\end{abstract}

Keywords: PIVAS, Construction, Cost, Charge, Survey

\footnotetext{
* Correspondence: zhlingli@sina.com

'Department of Pharmacy, Evidence-based Pharmacy Center, West China second hospital, Sichuan University. Key Laboratory of Birth Defects and Related Diseases of Women and Children (Sichuan University), Ministry of Education, Chengdu, China

Full list of author information is available at the end of the article
}

(c) The Author(s). 2020 Open Access This article is licensed under a Creative Commons Attribution 4.0 International License, which permits use, sharing, adaptation, distribution and reproduction in any medium or format, as long as you give appropriate credit to the original author(s) and the source, provide a link to the Creative Commons licence, and indicate if changes were made. The images or other third party material in this article are included in the article's Creative Commons licence, unless indicated otherwise in a credit line to the material. If material is not included in the article's Creative Commons licence and your intended use is not permitted by statutory regulation or exceeds the permitted use, you will need to obtain permission directly from the copyright holder. To view a copy of this licence, visit http://creativecommons.org/licenses/by/4.0/ The Creative Commons Public Domain Dedication waiver (http://creativecommons.org/publicdomain/zero/1.0/) applies to the data made available in this article, unless otherwise stated in a credit line to the data. 


\section{Background}

Pharmacy intravenous admixture services (PIVAS) is a medical department that integrates clinical pharmacy and scientific research according to international standards and good manufacturing practice (GMP) standards. In a clean operating environment, trained pharmacists or nurses in the PIVAS department conducted admixture of intravenous drugs according to operating procedures, including work with tumor chemotherapy drugs, total parenteral nutrition (TPN), general medicine and antibiotics. PIVAS also provided patients with rational drug use services $[1,2]$.

In 2002 and 2011, the "Regulations on the Administration of Pharmaceutical Affairs in Medical Institutions" published by the Ministry of Health of China clearly stated: medical institutions should establish PIVAS to achieve centralized admixture for tumor chemotherapy drugs and TPN. In 2010, the "Regulations on the Quality Management of Centralized Dispensing of Intravenous Drugs" clarified basic requirements and admixture procedures for PIVAS, marking the normalization of PIVAS in China [3].

In 1999, Shanghai Jing'an district central hospital established the first PIVAS in China. Other hospitals in China subsequently followed, and PIVAS now exists in more than 1100 hospitals [4]. With the continuous development of hospital and clinical pharmacies, PIVAS have significantly reduced patient morbidity and mortality caused by contaminated or incorrectly mixed intravenous infusions [5-7].

In 2016, Mi et al. [8] surveyed 97 PIVAS centers in Chinese hospitals to understand recent advances in PIVAS in China, but this cross-sectional study only included Level I and II hospitals, leaving the situation of Level III hospitals unclear. Additionally, $73 \%$ of the sample came from China's eastern provinces, meaning the sample did not adequately reflect the status of PIVAS throughout China.

Therefore, we used a multi-center cross-sectional survey to investigate the construction situation, cost and charges of PIVAS to provide a reference for the construction and development of PIVAS in mainland China.

\section{Methods}

\section{Study design}

This study comprises a multi-center cross-sectional survey conducted from March 2019 to April 2019.

\section{Participants}

PIVAS managers from each hospital were selected as survey respondents via the WeChat group of the Intravenous Dispensing Management and Application Branch of the China Medical Education Association, there are 300 members in the group.

\section{Data collection}

This study used self-developed questionnaires to collect data and investigate the construction situation of China's PIVAS. The contents of the questionnaire included: (1) basic participant information: region, level of their hospital, position; (2) basic situation of PIVAS: opening time, area, management mode, numbers of PIVAS, beds, open wards, equipment (biological safety cabinet, horizontal laminar flow table) and staff, and degree of recognition of doctors and nurses; (3) PIVAS costs and service charges: PIVAS service charge standard, intravenous admixture service costs, and profit and loss situation.

\section{Data analysis}

If the data were normally distributed, they were expressed as $\mathrm{x} \pm \mathrm{s}$, $\mathrm{t}$ test or analysis of variance was used. If the data were not normally distributed, the rank sum test was used. Categorical variables were analyzed by the chi-square test. The difference was statistically significant at $P<0.05$. Data were analyzed using SPSS 21.0 software (IBM Corp., Armonk, NY, U.S.A).

\section{Result}

Basic characteristics of PIVAS (Tables 1 and 2)

With the help of the questionnaire platform, 138 questionnaires were collected, of which 137 were valid questionnaires, for a response rate of $46 \%(138 / 300)$ and the rate of valid questionnaire of $99.3 \%(137 / 138)$.

The investigated PIVAS were located in 29 provinces, namely Anhui, Beijing, Chongqing, Fujian, Gansu, Guangdong, Guangxi, Guizhou, Hainan, Hebei, Heilongjiang, Henan, Hubei, Hunan, Jiangsu, Jiangxi, Jilin, Liaoning, Inner Mongolia, Qinghai, Shandong, Shanghai, Shanxi, Shaanxi, Sichuan, Tianjin, Xinjiang, Yunnan and Zhejiang. 56.2\% (77/137) of PIVAS were located in eastern China, 27.0\% (37/137) in western China, and $16.8 \%$ (23/137) in central China. The majority of PIVAS (74.5\%) were located in Level III Grade A hospitals.

The number of years of operations of PIVAS ranged from 1 to 22 (median: 6 years). Moreover, the area of PIVAS ranged between 100 and $1973 \mathrm{~m}^{2}$, with a median of $540 \mathrm{~m}^{2}$. The number of open wards ranged from 1 to 134 , with a median of 24 . In terms of PIVAS equipment, the mean number of biological safety cabinets is six, and the mean number of horizontal laminar flow tables is seven. Finally, the median numbers of pharmacists, nurses and workers were 12, 11.5 and 3, respectively.

$81.8 \%(112 / 137)$ of the hospitals surveyed had opened 1 PIVAS, while the remainder (22.6\%) has opened two or more PIVAS. In terms of scale, the largest group of PIVAS in the sample $(27.0 \%, 37 / 137)$ provided service for 501-1000 beds, with the next largest group (25.5\%, 35/137) serving 1501-1500 beds. Daily average infusion 
Table 1 Basic characteristics of PIVAS

\begin{tabular}{lll}
\hline Variable & Range (median) & Mean \pm SD \\
\hline The number of years of operations of PIVAS & $1-22$ years (6) & $6.31 \pm 3.88$ \\
Area $\left(\mathrm{m}^{2}\right)$ & $100-1973(540)$ & $582.22 \pm 281.64$ \\
Number of open wards & $1-134(24)$ & $26.83 \pm 20.48$ \\
Number of biological safety cabinet & $0-32(6)$ & $6.26 \pm 3.72$ \\
Number of horizontal laminar flow table & $0-27(6)$ & $7.23 \pm 3.97$ \\
Number of pharmacists & $1-110(12)$ & $17.18 \pm 16.04$ \\
Number of nurses & $4-52(11.5)$ & $13.46 \pm 8.50$ \\
Number of workers & $0-30(3)$ & $5.26 \pm 5.46$ \\
\hline
\end{tabular}

volume was mainly concentrated in the bands $0-1000$ bags $(29.9 \%, 41 / 137)$ and $1001-2000$ bags $(26.3 \%, 36 /$ 137). In terms of management mode, the vast majority of PIVAS $(65.0 \%, 89 / 137)$ used separate pharmacy management.

\section{The operations, charges and cost of PIVAS service}

\section{(Tables 3 and 4)}

Only 52.6\% (72/137) of PIVAS have charge standards, and $70.1 \%(96 / 137)$ operate at a loss. Most doctors $(67.4 \%, 88 / 137)$ and nurses $(86.8 \%, 119 / 137)$ recognized the performance of PIVAS, but based on labor results only $14.6 \%(20 / 137)$ of PIVAS were reflected in salary performance at the hospital level. The median costs of admix tumor chemotherapy drugs, TPN, general medicine and antibiotics were $20,35,4$ and 5 RMB, respectively.

\section{Subgroup analysis (Tables 5 and 6)}

In the subgroup analysis of different regions, we found only that the number of biological safety cabinets was

Table 2 Basic characteristics of PIVAS

\begin{tabular}{|c|c|c|}
\hline Variable & & Percentage $(\mathrm{n} /$ total)/Mean $\pm \mathrm{SD}$ \\
\hline \multirow[t]{3}{*}{ Region } & Eastern China & $56.2 \%(77 / 137)$ \\
\hline & Western China & $27.0 \%(37 / 137)$ \\
\hline & Central China & $16.8 \%(23 / 137)$ \\
\hline \multirow[t]{3}{*}{ Hospital level } & Level III Grade A hospital & $74.5 \%(102 / 137)$ \\
\hline & Level III Grade B hospital & $13.9 \%(19 / 137)$ \\
\hline & Level II Grade A hospital & $11.7 \%(16 / 137)$ \\
\hline \multirow[t]{3}{*}{ Number of PIVAS } & 1 & $81.8 \%(112 / 137)$ \\
\hline & 2 & $16.8 \%(23 / 137)$ \\
\hline & $\geq 3$ & $1.4 \%(2 / 137)$ \\
\hline \multirow[t]{6}{*}{ Number of beds } & $0-500$ & $22.6 \%(31 / 137)$ \\
\hline & $501-1000$ & $27.0 \%(37 / 137)$ \\
\hline & $1001-1500$ & $25.5 \%(35 / 137)$ \\
\hline & $1501-2000$ & $13.9 \%(19 / 137)$ \\
\hline & $2001-2500$ & $5.1 \%(7 / 137)$ \\
\hline & $\geq 2501$ & $5.8 \%(8 / 137)$ \\
\hline \multirow[t]{5}{*}{ PIVAS daily average infusion volume (bag) } & 0-1000 & $29.9 \%(41 / 137)$ \\
\hline & $1001-2000$ & $26.3 \%(36 / 137)$ \\
\hline & $2001-3000$ & $13.9 \%(19 / 137)$ \\
\hline & $3001-4000$ & $15.3 \%(21 / 137)$ \\
\hline & $\geq 4001$ & $14.6 \%(20 / 137)$ \\
\hline \multirow[t]{3}{*}{ Management mode } & Pharmacy management separately & $65.0 \%(89 / 137)$ \\
\hline & Pharmacist nurse co-manage & $10.2 \%(14 / 137)$ \\
\hline & Pharmacy-based, nursing department-assisted & $24.8 \%(34 / 137)$ \\
\hline
\end{tabular}


Table 3 the operations and charges of PIVAS

\begin{tabular}{|c|c|c|}
\hline Variable & & Percentage $(\mathrm{n} /$ total) $/$ Mean $\pm \mathrm{SD}$ \\
\hline \multirow[t]{2}{*}{ PIVAS charge standard } & Yes & $52.6 \%(72 / 137)$ \\
\hline & No & $47.4 \%(65 / 137)$ \\
\hline \multirow[t]{3}{*}{ PIVAS profit and loss situation } & Profit & $7.3 \%(10 / 137)$ \\
\hline & Loss & $70.1 \%(96 / 137)$ \\
\hline & Balance & $22.6 \%(31 / 137)$ \\
\hline \multirow[t]{5}{*}{ The degree of recognition of the doctors } & Very disagree & $0 \%(0 / 137)$ \\
\hline & Less agree & $4.4 \%(6 / 137)$ \\
\hline & General agree & $31.4 \%(43 / 137)$ \\
\hline & Slightly agree & $46.0 \%(63 / 137)$ \\
\hline & Very agree & $18.2 \%(25 / 137)$ \\
\hline \multirow[t]{5}{*}{ The degree of recognition of the nurses } & Very disagree & $0 \%(0 / 137)$ \\
\hline & Less agree & $3.6 \%(5 / 137)$ \\
\hline & General agree & $9.5 \%(13 / 137)$ \\
\hline & Slightly agree & $47.4 \%(65 / 137)$ \\
\hline & Very agree & $39.4 \%(54 / 137)$ \\
\hline \multirow[t]{3}{*}{ The labor results of PIVAS are reflected in the performance of the hospital level? } & Not reflected & $48.2 \%(66 / 137)$ \\
\hline & General & $37.2 \%(51 / 137)$ \\
\hline & Reflected & $14.6 \%(20 / 137)$ \\
\hline
\end{tabular}

higher in the eastern and central regions than in the western region $\left(X^{2}=4.355, P=0.015\right)$.

In the subgroup analysis of different levels of hospital, we found significant differences in daily average infusion volume $\left(X^{2}=21.468, P=0.006\right)$, and numbers of open wards $\left(X^{2}=11.726, P=0.003\right)$, biological safety cabinets $\left(X^{2}=3.613, P=0.030\right)$, horizontal laminar flow tables $\left(X^{2}=16.664, P=0.000\right)$, pharmacists $\left(X^{2}=18.588, P=\right.$ $0.000)$ and nurses $\left(X^{2}=7.111, P=0.029\right)$.

\section{Discussion}

To our knowledge, this was the first and largest crosssectional study to investigate the construction situation, costs and charges of PIVAS in China. A total of 137 hospitals located in China's eastern, western and central regions completed this survey, and so the research results are representative of the current status of PIVAS construction in China. Generally, PIVAS developed rapidly in China and are relatively large, reflected in larger site areas, numbers of open wards, quantities of equipment, and daily average infusion volumes.

Table 4 The cost of intravenous admixture service (yuan/bag) (including consumables, labor, depreciation of fixed assets)

\begin{tabular}{lll}
\hline Variable & Range (median) & Mean \pm SD \\
\hline Tumor chemotherapy drugs & $1-200(20)$ & $28.10 \pm 25.13$ \\
Total Parenteral Nutrition, TPN & $1-150(35)$ & $37.39 \pm 23.84$ \\
General medicine & $1-50(4)$ & $6.84 \pm 8.08$ \\
Antibiotics & $1-50(5)$ & $9.02 \pm 10.34$ \\
\hline
\end{tabular}

However, PIVAS in China are associated with many problems: (1) a unified management model is lacking, with the vast majority of PIVAS in China being separately managed by pharmacies, perhaps because most belonged to the pharmacy departments of their associated hospitals. However, two other management modes existed, meaning the advantages and disadvantages of different management models should be clarified to better control the quality of PIVAS operations; (2) Most provinces lack standards for charges, and most PIVAS operated at a loss, but many leaders in PIVAS thought the results of their labor were not reflected in hospital level salary performance, making it necessary to develop standards for PIVAS charges to motivate staff and highlight the value of their work. (3) The cost of admixing four kinds of medicine differed considerably among different PIVAS, perhaps because cost calculation methods differed among hospitals, highlighting the importance of developing unified standards for cost calculation.

Additionally, we analyze the relationship between PIVAS construction status for different provincial and hospital levels, and found no regional differences except in number of biological safety cabinets. This result showed similarity in development speed and scale between different regions, and suggested that national policies may contribute to the PIVAS development. Particularly, the publication of the "Regulations on the Quality Management of Centralized Dispensing of Intravenous Drugs" may promote PIVAS construction or 
Table 5 Basic characteristics of PIVAS in different region

\begin{tabular}{|c|c|c|c|c|c|c|}
\hline \multicolumn{2}{|l|}{ Variable } & \multirow{2}{*}{$\begin{array}{l}\begin{array}{l}\text { Eastern } \\
\text { China }\end{array} \\
17\end{array}$} & \multirow{2}{*}{$\begin{array}{l}\text { Western } \\
\text { China } \\
19\end{array}$} & \multirow{2}{*}{$\begin{array}{l}\text { Central } \\
\text { China } \\
5\end{array}$} & \multirow{2}{*}{$\begin{array}{l}x^{2} / F \\
10.937\end{array}$} & \multirow{2}{*}{$\begin{array}{l}P \\
0.205\end{array}$} \\
\hline PIVAS daily average infusion volume & $0-1000$ & & & & & \\
\hline & $1001-2000$ & 22 & 7 & 7 & & \\
\hline & $2001-3000$ & 13 & 3 & 3 & & \\
\hline & $3001-4000$ & 13 & 4 & 4 & & \\
\hline & $\geq 4001$ & 12 & 4 & 4 & & \\
\hline \multirow[t]{3}{*}{ Management mode } & Pharmacy management separately & 47 & 27 & 15 & 3.657 & 0.454 \\
\hline & Pharmacist nurse co-manage & 8 & 2 & 4 & & \\
\hline & $\begin{array}{l}\text { Pharmacy-based, nursing department- } \\
\text { assisted }\end{array}$ & 22 & 8 & 4 & & \\
\hline \multicolumn{2}{|c|}{ The number of years of operations of PIVAS } & $6.5 \pm 3.94$ & $6.5 \pm 4.54$ & $5.4 \pm 2.15$ & 0.807 & 0.668 \\
\hline \multicolumn{2}{|l|}{ Area $\left(m^{2}\right)$} & $611 \pm 276.21$ & $539 \pm 281.16$ & $556 \pm 301.29$ & 0.922 & 0.400 \\
\hline \multicolumn{2}{|l|}{ Number of open wards } & $28.3 \pm 22.06$ & $21.2 \pm 16.01$ & $31.1 \pm 20.30$ & 2.133 & 0.122 \\
\hline \multicolumn{2}{|l|}{ Number of biological safety cabinet } & $6.8 \pm 4.07$ & $4.8 \pm 2.84$ & $6.8 \pm 3.18$ & 4.355 & $0.015^{*}$ \\
\hline \multicolumn{2}{|l|}{ Number of horizontal laminar flow table } & $7.5 \pm 3.54$ & $6.2 \pm 3.83$ & $7.9 \pm 5.27$ & 1.669 & 0.192 \\
\hline \multicolumn{2}{|l|}{ Number of pharmacists } & $17.6 \pm 16.20$ & $15.4 \pm 15.17$ & $18.8 \pm 17.28$ & 0.359 & 0.699 \\
\hline \multicolumn{2}{|l|}{ Number of nurses } & $143 \pm 10.46$ & $13.2 \pm 6.96$ & $11.6 \pm 6.37$ & 0.284 & 0.754 \\
\hline
\end{tabular}

*: $P<0.05$

development. We also found that different levels of hospital differed significantly in daily average infusion volume, as well as numbers of open wards, equipment, and staff. This result was intuitive, with higher level hospitals being larger, and having more equipment, larger infusion volumes, and more numerous staff.

This study has some limitations. Firstly, this study did not use random sampling to select participants.
Naturally it is difficult to conduct a cross-sectional study using randomization given the absence of accurate numbers or clear listing of PIVAS in China. However, the study participants were drawn from 29 Chinese provinces, meaning the results are reasonably representative. Secondly, cross-sectional study could not make causal inferences, so further prospective research is needed to track the future development of PIVAS.

Table 6 Basic characteristics of PIVAS in different level of hospital

\begin{tabular}{|c|c|c|c|c|c|c|}
\hline \multicolumn{2}{|l|}{ Variable } & \multirow{2}{*}{$\begin{array}{l}\text { Level III Grade A } \\
\text { Hospital } \\
31\end{array}$} & \multirow{2}{*}{$\begin{array}{l}\text { Level III Grade B } \\
\text { Hospital } \\
4\end{array}$} & \multirow{2}{*}{$\begin{array}{l}\text { Level II Grade A } \\
\text { Hospital } \\
5\end{array}$} & \multirow{2}{*}{$\begin{array}{l}x^{2} / t \\
21.468\end{array}$} & \multirow{2}{*}{$\frac{P}{0.006^{*}}$} \\
\hline PIVAS daily average infusion & $0-1000$ & & & & & \\
\hline & $1001-2000$ & 22 & 5 & 9 & & \\
\hline & $2001-3000$ & 15 & 3 & 1 & & \\
\hline & $3001-4000$ & 15 & 6 & 0 & & \\
\hline & $\geq 4001$ & 19 & 1 & 0 & & \\
\hline \multirow[t]{3}{*}{ Management mode } & Pharmacy management separately & 72 & 9 & 8 & 7.457 & 0.114 \\
\hline & Pharmacist nurse co-manage & 7 & 3 & 4 & & \\
\hline & $\begin{array}{l}\text { Pharmacy-based, nursing } \\
\text { department-assisted }\end{array}$ & 23 & 7 & 4 & & \\
\hline \multicolumn{2}{|c|}{ The number of years of operations of PIVAS } & $6.6 \pm 3.87$ & $5.0 \pm 2.67$ & $6.1 \pm 4.96$ & 1.403 & 0.249 \\
\hline \multicolumn{2}{|l|}{ Area $\left(m^{2}\right)$} & $604.7 \pm 297.3$ & $588.9 \pm 241.83$ & $431.1 \pm 160.67$ & 2.700 & 0.071 \\
\hline \multicolumn{2}{|l|}{ Number of open wards } & $29.9 \pm 21.86$ & $21.1 \pm 14.09$ & $14.2 \pm 8.56$ & 11.726 & $0.003^{*}$ \\
\hline \multicolumn{2}{|c|}{ Number of biological safety cabinet } & $6.6 \pm 4.00$ & $6.2 \pm 2.67$ & $4.0 \pm 1.71$ & 3.613 & $0.030^{*}$ \\
\hline \multicolumn{2}{|c|}{ Number of horizontal laminar flow table } & $7.8 \pm 4.26$ & $6.8 \pm 2.50$ & $4.3 \pm 1.40$ & 16.664 & $0.000^{*}$ \\
\hline \multicolumn{2}{|l|}{ Number of pharmacists } & $19.3 \pm 16.97$ & $13.9 \pm 13.14$ & $7.4 \pm 6.26$ & 18.588 & $0.000^{*}$ \\
\hline \multicolumn{2}{|l|}{ Number of nurses } & $13.8 \pm 6.62$ & $7.3 \pm 2.14$ & $18.0 \pm 15.82$ & 7.111 & $0.029^{*}$ \\
\hline
\end{tabular}




\section{Conclusion}

The development of PIVAS in China has been fast and PIVAS in China are also relatively large. The main problems are the lack of charge standards in most provinces and differences in PIVAS construction among hospitals in China. Therefore, it is necessary to develop standards for PIVAS construction and charges to provide a reference for the future development of PIVAS.

\section{Abbreviations}

PIVAS: Pharmacy intravenous admixture services; TPN: Total parenteral nutrition; GMP: Good manufacturing practice

\section{Acknowledgments}

We thank Liwen Bianji, Edanz Editing China (www.liwenbianji.cn/ac), for editing the English text of a draft of this manuscript.

\section{Authors' contributions}

YCS and KBY designed the review, collected data, carried out analysis and interpretation of the data and wrote the review. YD designed the review, collected data, checked the data and wrote the review. ZLL designed the review, commented on drafts for previous version. All the authors read and approved the final version of the manuscript.

\section{Funding}

This study was funded by Sichuan Health and Wellness Committee: Evidence-based construction of clinical drug route for children with tic disorder (18PJ528). The sponsor had no role in the study design, writing of the manuscript, or decision to submit this or future manuscripts for publication.

\section{Availability of data and materials}

The datasets generated and/or analyzed during the current study are not publicly available because they are subject to the West China Second University Hospital, Sichuan University. However, the data and materials are available from the corresponding author on reasonable request.

\section{Ethics approval and consent to participate}

All participants completed and signed an informed consent form before the survey started. This study was approved by the Institutional Review Board of West China Second University Hospital, Sichuan University.

\section{Consent for publication}

As this manuscript contains no individual personal data, this section is not applicable.

\section{Competing interests}

The authors declare that they have no competing interest.

\section{Author details}

'Department of Pharmacy, Evidence-based Pharmacy Center, West China second hospital, Sichuan University. Key Laboratory of Birth Defects and Related Diseases of Women and Children (Sichuan University), Ministry of Education, Chengdu, China. ${ }^{2}$ Department of Epidemiology, West China School of Public Health, and West China Fourth Hospital, Sichuan University, Chengdu, China. ${ }^{3}$ Department of Pediatric clinic, West China second hospital, Sichuan University, Chengdu, China. ${ }^{4}$ Department of Children's Genetic Endocrinology and Metabolism, West China Second University Hospital, Sichuan University, Sichuan University, Chengdu, China.

Received: 13 August 2019 Accepted: 18 May 2020

Published online: 24 June 2020

\section{References}

1. Huiming C, Yanqiu F, Shen J. The present situation of pharmacy intravenous admixture sevices of 11 hospitals in Shanghai. Pharmaceutical Care and Research. 2004;4(3):201

2. Xie S. Standardization of pharmacy intravenous admixture service. Chinese Journal of Modern Applied Pharmacy. 2011;28(10):965-8.
3. Chuanzhe K, Zhu L, Nian L, Lihui Z, Wang Q, Wang F, Hanfen Z, Yuxia H. The construction mode and workflow optimization Design of Pharmacy Intravenous Admixture Service. J Pediatr Pharm. 2017;23(01):46-9.

4. Yang W, Tan J. Establishment and operation of pharmacy intravenous admixture service center in our hospital. Gansu Medical Journal. 2017;36(08): 692-4.

5. American Society of Health System Pharmacists. ASHP guidelines on compounding sterile preparations. Am J Health Syst Pharm. 2014;71:145-66

6. Rich DS, Fricker MP, Cohen MR, et al. Guidelines for the safe preparation of sterile compounds: results of the ISMP sterile preparation compounding safety summit of October 2011. Hosp Pharm. 2013:48:282-94.

7. Allwood MC. Practical guides. I: Central intravenous additive services. J Clin Pharm Ther. 1994:19:137-45.

8. Mi W, Li L, Zhang Y, Yang P, Miao P, Liu X. Chinese centralised intravenous admixture service (CIVAS), an emerging pharmaceutical industry: survey of the recent advances of CIVAS in China. Eur J Hosp Pharm. 2018;25(3):165-8.

\section{Publisher's Note}

Springer Nature remains neutral with regard to jurisdictional claims in published maps and institutional affiliations.
Ready to submit your research? Choose BMC and benefit from:

- fast, convenient online submission

- thorough peer review by experienced researchers in your field

- rapid publication on acceptance

- support for research data, including large and complex data types

- gold Open Access which fosters wider collaboration and increased citations

- maximum visibility for your research: over $100 \mathrm{M}$ website views per year

At BMC, research is always in progress.

Learn more biomedcentral.com/submission 